\title{
IMPACT OF COLOUR ON DEPRESSION, ANXIETY AND STRESS LEVELS OF PHYSICALLY DISABLED PATIENTS IN HEALTH CARE FACILITIES
}

\author{
A Case in a Rehabilitation Centre at Ragama, Sri Lanka
}

HETTIARACHCHI. A . A ${ }^{1}$ \& PERERA. U.D.R ${ }^{2}$

${ }_{1,2}$ Department of Architecture, University of Moratuwa, Sri Lanka

1anishkah@uom.lk, ${ }^{2}$ dushanrandika.perera@gmail.com

\begin{abstract}
Physically disabled community in Sri Lanka is not receiving sufficient attention with reference to the conduciveness of their living environments. The patients who are harrowed with mobility impairments should be supported to overcome challenges which hinder the smooth functioning of day today physical activities while maintaining their psychological health by incorporating disabled-friendly, optimum healing design interventions. In view of this, an attempt was made to determine the impact of interior colours to reduce depression, anxiety and stress levels of disabled individuals. The investigation was executed with reference to wall colour of patient's $(n=15)$ bedrooms of a selected rehabilitation centre, at Ragama. The impact of three selected hues (blue, yellow and green) were tested by installing colour panels on the sidewall of the beds, allowing the participants to be exposed to each colour for three consecutive days. Depression, anxiety and stress levels of participants were measured using DASS-21. Impact of green colour was found to be more favourable to reduce depression, anxiety and stress levels of participants over blue and yellow. It is recommended to extend this study further to test different hues, shades and intensities of green colour with long-term exposure, to enhance psychological health and well-being of disabled patients in health care facilities.
\end{abstract}

Keywords: Physically disabled patients, Interior Colour, DASS-21, Healthcare facilities

\section{Background to the Research}

As stipulated in the protection of the rights of persons with disabilities act (No. 28 of 1996) - sect 36, " a person with disability means any person who, as a result of any deficiency in his physical or mental capabilities, whether congenital or not, is unable by himself to ensure for himself, wholly or partly, the necessities of life". According to the statistics of World Health Organisation (2020), 15\% of the global population (;1 billion individuals), experiences some form of disability. One-fifth of the assessed worldwide aggregate (110 million -190 million individuals) experience significant disabilities. People with disabilities are more likely to encounter adverse physical, psychological, social, economic and other issues over people without disabilities namely; higher rates of unemployment, higher poverty rates, poorer health outcomes and lesser opportunities in education.

Developing countries, are reported to have a higher disability prevalence rate $($ WHO,2020). According to 2012 statistics, around $8.7 \%$ of the total population (above the age of 5 years) in Sri Lanka lives with disabilities. It is estimated that about 300,000 people in the age group between 18 to 60 have some form of disability out of which around 57\% are male while 43\% are female. As per Masridin (2019), individuals with impeded mobility is a group (physically disabled community) of people under the larger umbrella of people with disability. 734,213 individuals (over the age of 5 years) were reported to have mobility related disabilities (Census,2012). The issues encountered by physically impaired community in Sri Lanka and their versatility is not being well addressed by the relevant authorities.

As highlighted by Weiss (2012), individuals who encounter a disability for the first time may have 
to cope with a process of adjustment to an array of life transitions including changes in the system of living, value changes and experience an array of disability related issues across their life span, causing enormous distress. They also will have to deal with sociological challenges related to the role of family, cross-cultural issues, adjustments, social treatment, social status and the consequences of negative attitude towards people with disabilities as a whole. Weiss (2012) further clarifies that, similar to enduring a grieving process associated with loss (death, relationship breakup, loss of job, property or reputation) or major life changes, the involvement of an injury that leads to a physical or mental inability could be associated with four sequential stages namely; shock, denial, anger/depression and adjustment/acceptance. During this process an individual will grieve for the changes in their body image, function, loss of future expectations or former satisfaction based upon any function that has been lost.

A mobility impairment or physical disabilities will not only influence an individual's physical wellbeing associated with day today life, but they also have to face social and psychological problems, immensely affecting their mental health and wellbeing (Idrees and Ilyas, 2012). Psychological issues are considered to be a major vindication of the disabled in comparison to the physiological problems, being the deciding factor on the way they think about themselves, their goals and the overall attitude towards life ahead. On the other hand, disabled people have always been discriminated and stigmatized across cultures for thousands of years (Idrees and Ilyas, 2012). The negative stigma these groups have to confront is still considered to be very high even though it is proven that several groups of people with disabilities are capable of doing the same amount of labour and activity compared to the normal individual. The struggle of coping with such stressors will lead to more serious psychiatric issues such as depression, anxiety, stress and losing their will to live.

Depression is a severe mood disorder covering a variety of negative moods and behavioural changes. It is the fourth leading cause of social incapacitation in the world (Prabhakar, 2013). According to Diagnostic and Statistical Manual of Mental Disorders $5^{\text {th }}$ Edition (DSM-5), Depression (major depressive disorder) is a common and serious medical illness that negatively affects the way an individual feel, think and act. To make a diagnosis of depression, an individual should experience persistent feelings of either sadness or loss of interest/pleasure in activities they once enjoyed, as a main symptom for a period of 2 weeks or more together with five or more symptoms of decrease or increase in appetite/weight, fatigue or loss of energy, feeling of worthlessness/guilt, lack of concentration and recurrent suicidal ideation(American Psychiatric Association, 2013). Apart from the emotional problems caused by depression, individuals can also be present with physical symptoms such as chronic pain or digestive issues.

Individuals with Generalised Anxiety Disorder(GAD) experience chronic, constant and often unsubstantiated fear or worry with reference to family, health, financial status etc. Such worries can continue throughout the day, in some cases every day, disrupting social activities, family, work or school. According to DMS 5, symptoms of GAD include but are not limited to, excessive anxiety and worry occurring for at least 6 months and three of the six symptoms namely, restlessness, fatigue, difficulty concentration, irritability, muscle tension, sleep disturbance (American Psychiatric Association, 2013).

Stress is a negative emotional experience followed by predictable changes in biochemistry, physiology, cognition and actions that are either aimed at altering the stressful event or accommodating its effects (Baum, 1990). When physical or psychological well-being is disrupted or threatened, it is a somewhat unspecified biological, emotional, and behavioural mechanism. Usually, it entails increased physiological enthusiasm, followed by negative feelings, including anxiety. Stress happens when an individual is overwhelmed by aspects of the environment; that is, a person feels stressed when too much is expected or when an incident appears terrifying or troubling.

Various psychological management interventions like Cognitive Behavioural Therapy (CBT) can aid individuals with disability to advance through the stages of disability and help them with settling any difficulties they may encounter along the way. The result can be an increase in the person's self-esteem and confidence (Weiss, 2012), ensuring mental well-being characterised by reduced levels of depression, stress and anxiety. However, this process of healing and empowerment should be done holistically with friendly and supportive people/society around as well as a conducive living environment for a positive outcome. 


\section{Research Need}

This investigation looked in to the need to explore the manner as to how the patients who are affected with mobility impairments should be supported via incorporating Architectural design interventions to overcome their psycho-physiological challenges, ensuring their psychological health and well-being. An Architects role here would be to support the patients by designing disabled-friendly, conducive, optimal healing environments consisting of psychophysically comfortable, healing spaces to uplift their overall well-being.

\section{Review of Literature}

An optimal healing environment (OHE) as highlighted by Kreitzer and Zborowsky (2014), should be designed considering the deep and dynamic interplay of the parameters of disabled people, the healing process, culture as well as the place to achieve maximum positive outcome for the patients. The place element focuses on the physical space where care is provided (health care facilities, half way homes, hospitals ...etc) and the context that surrounds the patient, family and caregivers. According to Kreitzer and Zborowsky (2014) parameters of place in the OHE model includes access to nature, positive distractions, aesthetics, ambient environment and eco-system sustainability as elaborated below.

\begin{tabular}{|l|l|}
\hline OHE Place Component & Definition \\
\hline $\begin{array}{l}\text { Meets functional } \\
\text { Requirements }\end{array}$ & $\begin{array}{l}\text { Functional requirements are identified during the programming phase of the } \\
\text { design process. These requirements include patient and staff safety, space for } \\
\text { social support, and staff work areas, among others.(www.fgiguidelines.org) }\end{array}$ \\
\hline Access to nature & $\begin{array}{l}\text { Actual or visual access to natural settings or designed nature settings. } \\
\text { Access to daylight. }\end{array}$ \\
\hline Positive distractions & $\begin{array}{l}\text { Includes elements of the design environment that are of a 2-D or 3-D nature; } \\
\text { artwork, water features, fire places. }\end{array}$ \\
\hline Aesthetics & $\begin{array}{l}\text { Includes the design elements of colour, texture, shape, form and volume; } \\
\text { furniture, fabric, room layout etc. }\end{array}$ \\
\hline Ambient environment & Includes the elements of artificial light, sound, odor, air temperature, air quality. \\
\hline $\begin{array}{l}\text { Supports a Sustainable } \\
\text { Ecosystem }\end{array}$ & $\begin{array}{l}\text { Includes the economic, social and ecological impact of the design elements of } \\
\text { the building and the impact of any construction. }\end{array}$ \\
\hline
\end{tabular}

Table 1 - Elements of place: Design parameters which impact the process of facilitating OHE (Source: Zborowsky and Kreitzer - 2014)

Out of the array of design elements discussed under OHE for disabled, the current investigation mainly focuses on the impact of colour to induce therapeutic/healing effects on physically disabled patients. Colours define the human visual perception of the natural and man-made world and plays a critical role in how the spaces are being perceived by the individuals and how the responses, reactions or behaviours are triggered based on the thoughts, emotions and psychological reactions that stem due to presence of diverse colours in the place component. Each colour is made up of a specific wavelength of electromagnetic energy which represent a fraction of a broader visual spectrum ranging from 380 to about 750 nanometres (Starr, 2005). The colour vision is a result of the wavelengths that are reflected back to human eyes.

As identified by Zborowsky and Kreitzer (2014) colour has been identified as an aesthetic design element in OHE. However, the role of colour in Architectural spaces is not relegated to decoration alone (Mahnke, 1996). Colours are used in Architecture beyond aesthetics (visual attraction) as a tool of communication and to create ambiance of space associated with corresponding moods, emotions and behaviour (Mahnke, 1996). Colour associated thoughts, meanings and symbolism of individuals to the most part will vary based on their colour preference, socio cultural religious background, age, gender and personal experiences etc. However, there are established universal meanings, symbolisms, psychophysiological impacts of colours based on whether they are warm colours (long wave, low frequency, less energy) or cool colours (short waves, high frequency). Accordingly, warm colours, namely; red, orange and yellow, are established to have a stimulating, arousing and energizing effect on humans while cool colours (blue, green, purple) are found to pacify, calm and relax individuals (Wexner, 1954,. Itten, 1973,.Birren, 1988,. Mahnke, 1996). According to Eiseman (2006), "people find cool shades of blue and green to be relaxing because these colours remind of nature" 
Colours have been found to be having a healing impact on humans. As stated by Nightingale (1860), "little do we know about the way in which we are affected by form, colour and light. We know that they have an actual physical effect. Variety of form and brilliancy of colour in the objects presented to patients are actual means of recovery".

Chromotherapy is a method of treatment that uses the visible spectrum (colorus) of electromagnetic radiation to heal ailments. It is evident that the healing quality of colour has been used since the emergence of ancient civilizations such as Greek, Egyptian, Chinese and Indian. Principles of chromotherapy distinguishes seven "Chakras'; pulsating energy points in the human body which energizes and sustains certain associating major endocrine glands and organs corresponding to particular states of consciousnesses, personality types and endocrine secretions (Klotsche, 1993). Each chakra is found to be responsive to a different colour associated with specific healing impacts on the human's physical health as well as mental health (Richardson,2019). Colour, being another form of pulsating energy becomes an agent via the phenomenon of harmonic frequency to energize and bring back the lost tune of weak chakras corresponding with associated glands, organs and systems of the human body to restore physical and psychological well-being.

For instance, the Solar Plexus Chakra (Manipurna) located at the navel is associated with colour yellow which stimulates mental faculties, and reawakens enthusiasm for life, counteracting depression (Richardson,2019). The Heart Chakra (Anahata), located at the centre of the chest, being the core uniting the physical with the spiritual, bringing wholeness and overall well-being of the individual is explained to correspond with colour green (Richardson,2019). Blue is the colour for Throat Chakra (Visuddha), the psychic centre associated with communication including creative processes like speaking, listening, chanting, telepathy and arts. Imbalances with this psychic centre leads to fear, doubt, uncertainty and habitual living, leading to poor mental health which can be restored by calming, healing and relaxing vibes of blue (Richardson,2019).

Colours have been found to induce positive effects on the recovery of patients with psychiatric imbalances since ancient times. As reported in New York Times(1902), "Patients with acute mania were put in black rooms, patients with melancholia in red rooms; blue and green rooms for the boisterous, and a white room for the person who is practically well." In a study executed by Barrick, Taylor and Correa, 2002, colour sensitivity was found to be significantly correlated to individuals with mood disorders. Accordingly, it is vital to integrate conducive colours which can induce positive and conducive impacts on distressed, depressed and anxious individuals in their most inhibited environments.

\subsection{IMPACT OF COLOUR ON ANXIETY:}

Jacob and Suess (1975) who investigated the effects of colour on anxiety observed higher anxiety scores under the red and yellow conditions than in the green and blue situations. As revealed in a study done by Mahnke (1996), most of the subjects associated red light with anxiety, blue and green with calming feelings of relief, orange with arousal but less arousing than red and more pleasantly stimulating; and violet with mystical feelings. Gerard (1958) cited in Lubos (2012) found that red produced feelings of arousal, and was disturbing to anxious or tense subjects, while blue generated feelings of tranquillity and well-being, inducing a calming effect. Studies have shown that yellow produces statistically significant biological responses and higher anxiety-state scores ( Dearing and Singg ,1996). Contrastingly, Nolan, et al(1995) identifies yellow as a soft warm colour which could reduce the anxiety levels of patients.

\subsection{IMPACT OF COLOUR ON STRESS:}

In a study conducted by Kutchma (2003), it was found that subjects in red room conditions had higher stress rating scores compared to green or white room conditions. Blue colour was found to induce a stronger effect on the reduction of stress levels (Lubos, 2012). Calmer emotions were generally noticed by patients who were exposed to a blue room; pleasant, calming, restful and supporting concentration, thinking and meditation, suggesting the colours ability to reduce stress levels (Mahnke, 1996). Spending time in natural green environments or even looking at pictures of green scenery in nature has been found to be linked with stress relief ( Gamble, Howard and Howard, 2014).

\subsection{IMPACT OF COLOUR ON DEPRESSION:}

Some studies have pointed out that patients with depressive disorders should not be exposed to blue or 
other cold colours as it could aggravate the disease conditions (Zhou, 2013). Woodson (1981) while identifying blue as a colour which induces cool, comfort, protective and calming psychological impacts, has also discussed slightly depressing nature triggered by its darker versions. As cited in Kutchma (2003), depressing effects of blue has been also identified by Hamilton and Newport (1989). Similarly, some patients found blue to be cool, depressing and sad in a study executed by (Mahnke,1996). It was indicated that depressed patients preferred the cold colours; blue, purple, suggestively due to the psychological belief that the cold colours could stabilize and calm down a restless or uneasy mood (Nagumo, 2006).

Carefully scrutinizing the array of existing literature on the conducive psychological impacts of colours, a shade each of green, blue and yellow were selected to test the favourable effects on reducing depression, anxiety and stress of patients with mobility impairments.

\section{Aims and Objectives}

The main objective of this study is to look in to the impact of Architectural design of a space in improving the psychological health; reducing depression, stress, anxiety of mobility impaired (physically disabled) patients with reference to wall colours of common residential-healthcare accommodation spaces (rooms).

\section{Theoretical Framework}

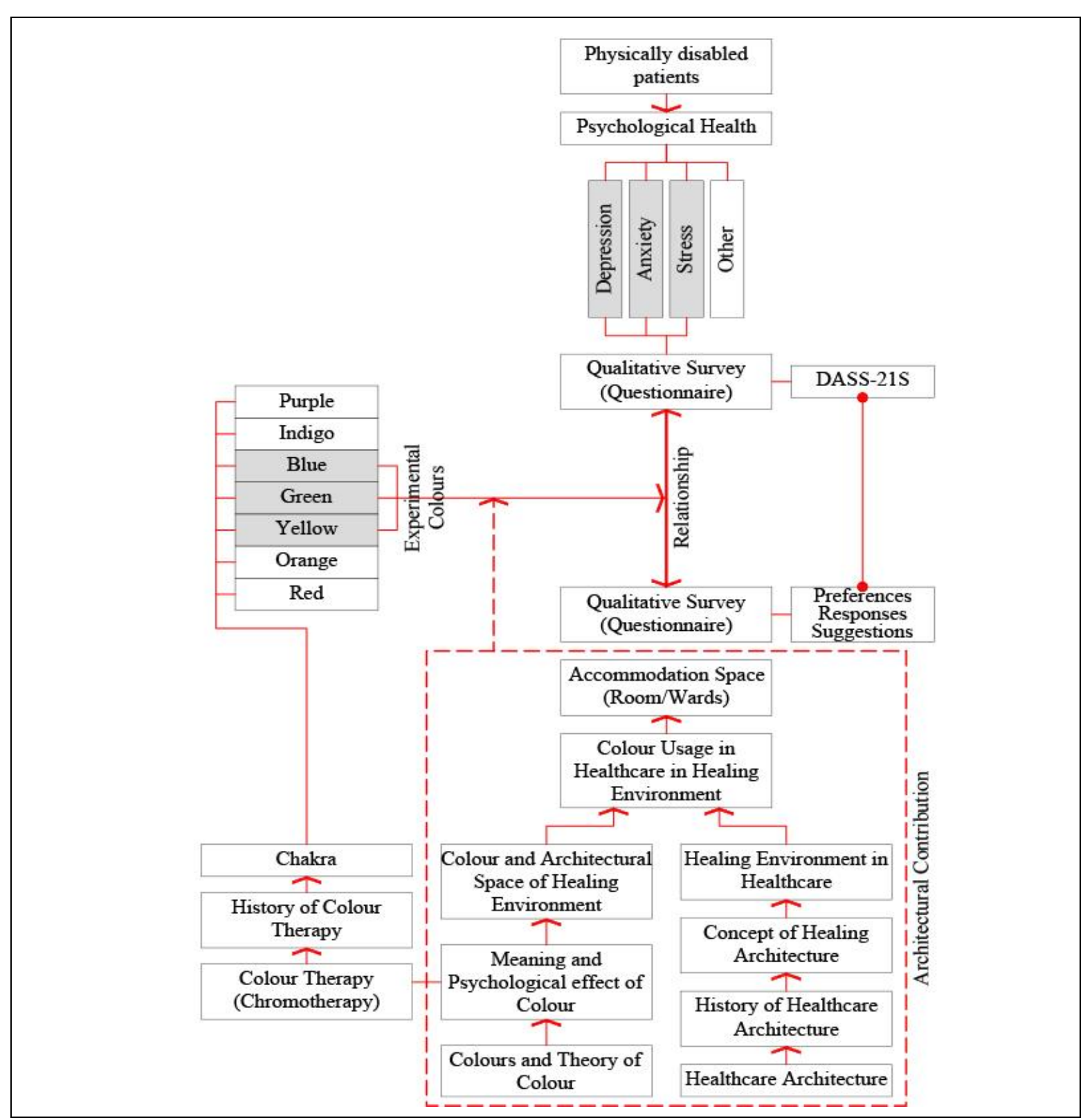

Figure 1, Theoretical framework derived from the review of literature. 


\section{Scope and Limitation}

The study was limited to the healing effect of only three selected colour shades and their impacts on the psychological state of mobility impaired patients, only focusing on their depression, anxiety and stress levels. The case study was conducted in a selected rehabilitation centre at Ragama. The survey was limited to a sample of physically disabled male patients $(\mathrm{n}=15)$ who are suffering from the same illness and residing within accommodation spaces (bedrooms) in same premises with similar dimensions, finishes, textures, volumes, materials and lighting.

\section{Methodology}

All necessary ethical guidelines were incorporated in laying down the methodology in order to ensure that the daily routines and well-being of the participants was not compromised. Accommodation spaces (rooms) of 15 patients were tested by introducing colour panels to the sidewalls of the bed, being the most visible area providing maximum visual connection with the patient, to induce the maximum impact. Other affective parameters such as room temperature, lighting level, humidity and wind velocity were maintained at a constant level. The data collection was done during the daytime with natural lighting conditions $(9.00$ a.m - 11.a.m).

Considering the sensitiveness of the participants it was vital to select colours that were perceived to be as soothing by them and not irritating or inducing adverse effects. Accordingly, a pilot study was conducted with the patients of the same facility. They were provided with a colour palette with three different shades of green, blue and yellow; a dark shade, a moderated shade and a lighter shade and were requested to choose the best colour they prefer to incorporate in their rooms. Afterwards, the three final shades were selected based on the preference of the majority of participants (figure 2).
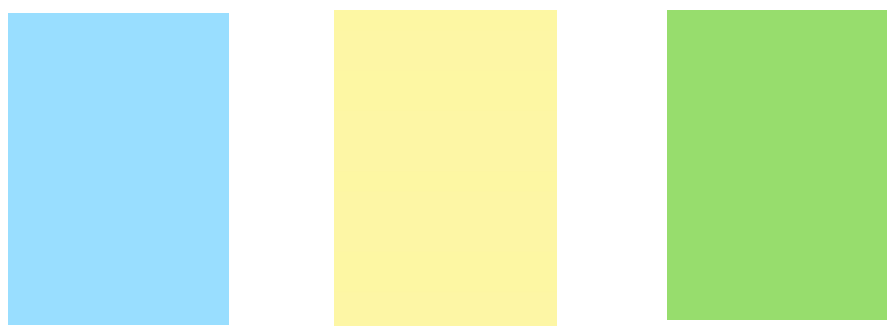

Figure 2, Selected shades of blue (RGB:153,222,255), yellow (RGB:253,246,165) and green

(RGB: 151,221,109)

A1 size (594x $841 \mathrm{~mm}$ ) colour panels were set up in 7 rooms in identical locations (patient's bed side wall) as shown in figures 3,4 without any physical interference or damage to the interior finishes of the room. Data was collected with reference to the existing colour scheme (white) as a control condition, followed by exposure to blue, yellow and green colours respectively. The patients were exposed to each colour condition for a period of 3 days.
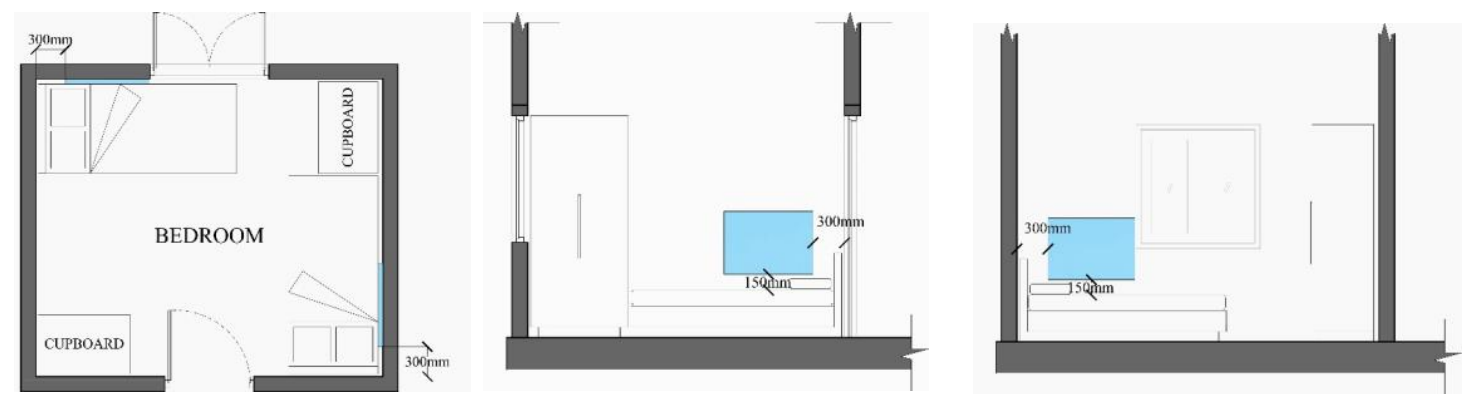

Figure 3, Details on colour installation - Blue colour Panels

Both quantitative and qualitative methods were used in the data collection; questionnaire surveys, observations and photographic study. Depression Anxiety Stress Scale (DASS-21S) was adopted to figure out the psychological levels under each colour exposure. The DAS levels were reported under a spectrum 
of five levels; Normal, Mid, Moderate, Severe and Extremely Severe. Recommended cut-off scores for conventional severity labels (normal, moderate, severe) adopted are as follows: (Scores on the DASS-21 needs to be multiplied by 2 to calculate the final score).

$\begin{array}{llll} & \text { Depression } & \text { Anxiety } & \text { Stress } \\ \text { Normal } & 0-9 & 0-7 & 0-14 \\ \text { Mid } & 10-13 & 8-9 & 15-18 \\ \text { Moderate } & 14-20 & 10-14 & 19-25 \\ \text { Severe } & 21-27 & 15-19 & 26-33 \\ \text { Extremely severe } & 28+ & 20+ & 34+\end{array}$

Table 2: Recommended cut-off scores for conventional severity labels (normal, moderate, severe)

(Source: Lovibond, S.H., \& Lovibond, P.F. (1995))

A questionnaire survey was incorporated (Q2) to figure out the qualitative data on perceived comfort and satisfaction with reference to the introduced colour conditions.

\section{Research findings}

The overall results of the quantitative study (Q1 - DASS 21) demonstrated considerable differences in the psychological states of the participants (depression, anxiety, stress levels) with reference to the existing colour conditions over the introduced blue, yellow, green colour conditions.

\subsection{DEPRESSION LEVELS}

As elaborated in Fig 4, colour green produced the highest improvement in the levels of depression ("Normal" range: $80 \%$ and "Mid" range: 20\%) compared to the existing colour scheme ("Normal" range: $40 \%$ and "Mid" range: $60 \%$ ) followed by yellow and blue ("Normal" range: $60 \%$ and "Mid" range $40 \%$ ). Therefore, Colour green was revealed to be supportive in the overall improvement of psychological health, considering depression levels. A tendency of blue colour to aggravate depression levels (Woodson,1981., Hamilton and Newport,1989., Zhou, 2013 and Mahnke, 1996) was not demonstrated in this study.

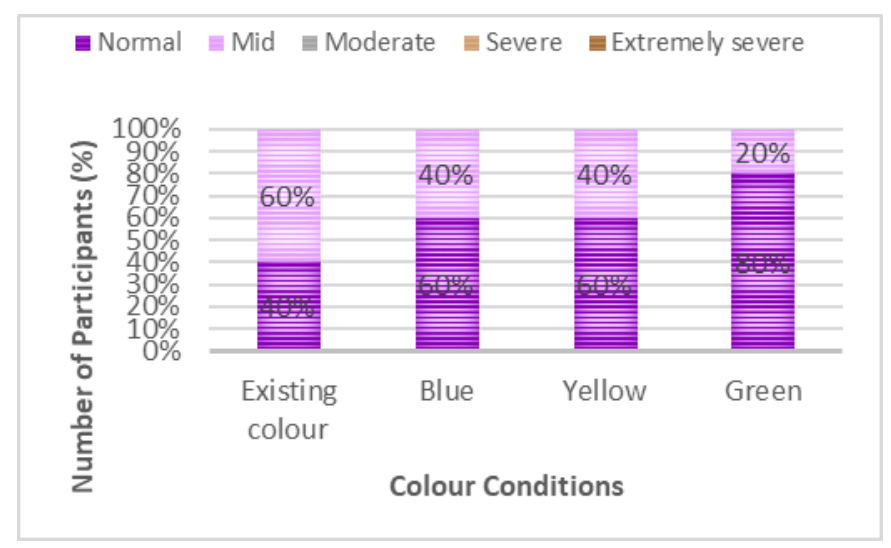

Figure 4, Summary of Depression levels of participants in relation to the existing colour (white) and introduced blue, yellow and green colours.

\subsection{ANXIETY LEVELS}

As seen in Fig 5 the highest improvement in the levels of anxiety was seen again under the introduced green colour condition ("Normal" range: 60\%, "Mid" range: 33\% and "Severe" range: $7 \%$ ) followed by yellow ("Normal" range: $60 \%$ and "Mid" range $27 \%$ and "Severe" range: $13 \%$ ) and blue ("Normal" range: $53 \%$ and "Mid" range 40\% and "Severe" range: 7\%). Again, colour green was seen as the best colour choice out of the introduced three colours for the overall improvement of anxiety levels followed by blue as also observed by Gerard (1958) and Mahnke (1996). Unlike other colours, 13\% of the participants experienced a moderate level of anxiety during exposure to colour Yellow. This observation supports the findings of Jacob 
and Suess (1975) and Dearing \& Singg (1996) where colour Yellow was found to be aggravating levels of anxiety.

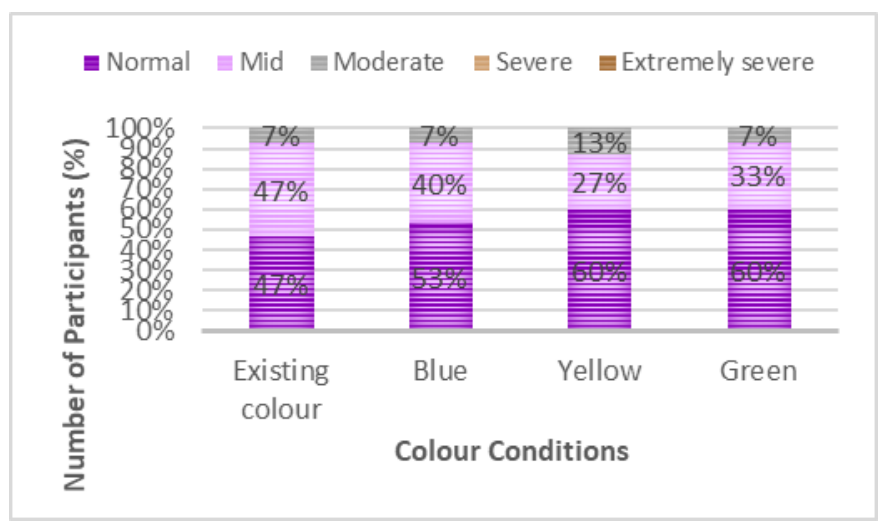

Figure 5: Summary of Anxiety level of participants with the existing colour (white) and introduced blue, yellow and green colour.

\subsection{STRESS LEVELS}

As shown in Fig 6, stress levels of the participants across all colour conditions did not demonstrate a significant improvement compared to the stress levels under the existing colour condition. Colour green showed the best results out of the three introduced colours ("Normal" range: 73\%, "Mid" range: 20\% and "Severe" range: $07 \%$ ) which however was similar to the existing colour conditions. Second best result was seen under colour blue ("Normal" range: 67\% and "Mid" range 27\% and "Severe" range: 07\%) followed by colour yellow ("Normal" range: $67 \%$ and "Mid" range 20\% and "Severe" range: $13 \%$ ). Therefore, out of the introduced colours, green was seen as the best colour for the overall improvement of stress levels parallel with findings of Kutchma (2003) and (Gamble, Howard and Howard, 2014), followed by colour blue, in alignment with Lubos (2012). On the other hand, colour yellow was found to be aggravating stress levels, even though not significantly, compared to other colours, supposedly due to its stimulating effect on individuals as explained by Gebert (1977).

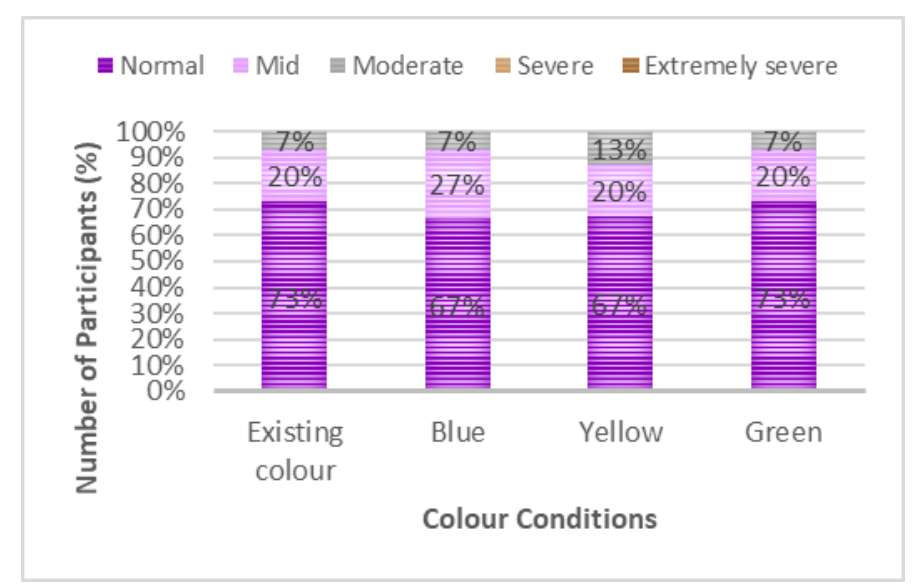

Figure 6: Summary of stress level of participants with the existing colour (white) and introduced blue, yellow and green colours.

Accordingly, as identified by DASS -21, color green was found to be reducing depression, anxiety and stress levels of patients compared to blue and yellow.

\subsection{QUALITATIVE DATA ANALYSIS}

Findings of the qualitative data (Q2) demonstrated similar impacts with reference to the colours tested. A majority of the participants were satisfied with the introduced green colour $(80 \%)$ followed by blue $(73 \%)$. Only $47 \%$ of participants were satisfied regarding the exposure to yellow colour. The perceived comfort 
was seen as high with reference to green (73\%), followed by blue (47\%) and yellow (40\%). On the other hand, a majority perceived colour yellow as inducing an uncomfortable experience (53\%) compared to blue $(20 \%)$ and green $(20 \%)$.

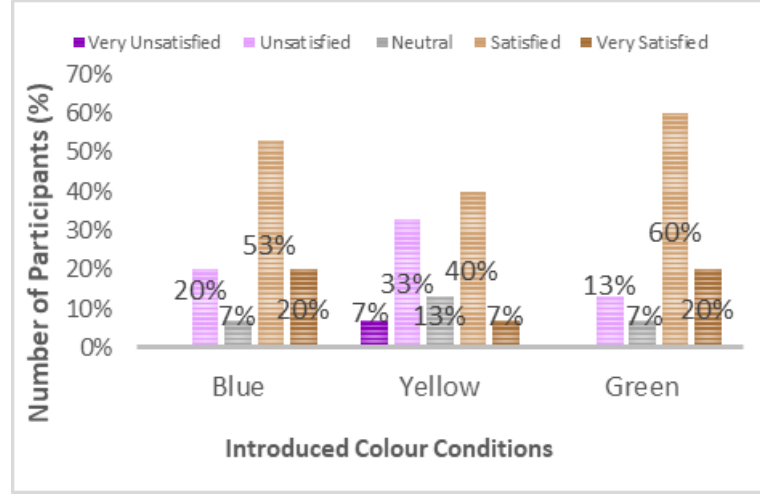

Figure 7: Perceived level of satisfaction in exposure to blue, yellow and green colours

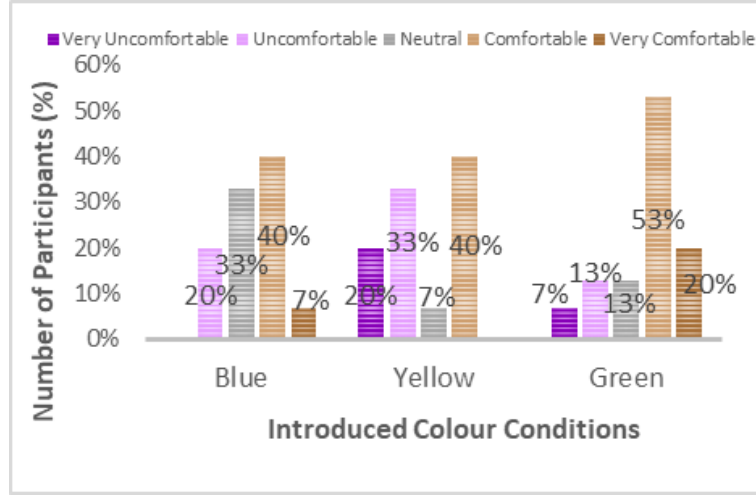

Figure 8: Perceived level of comfort in exposure to blue, yellow and green colours.

\section{Conclusions and future recommendations.}

The findings of the study revealed positive impacts of colour on the psychological condition of physically disabled patients. Aligned with literature, colour Green was found to be inducing most conducive impacts followed by blue, in reducing depression, anxiety and stress levels of participants. The positive impacts of the shade of Green tested is quite evident when combining the findings of both DASS - 21 and Q2 together. Colour Green was significant in the patients' perceived level of satisfaction and comfort in their respective accommodation spaces, compared to Blue and Yellow. On the other end, the possible impact of colour Yellow in aggravating the perceived stress and anxiety levels was revealed through DASS 21. The positive impacts of colour Green can be supposedly associated with its connection to nature and the established pacifying, calming and relaxing effects (Wexner,1954., Itten,1973,.Birren, 1988,. Mahnke,1996 and Eiseman,2006).

Accordingly, the current investigation clearly identifies the potential of incorporating colour Green in health care facilities for patients who are affected with mobility impairments, in order to ensure their psychological health and well-being, by reducing depression, anxiety and stress levels. It is recommended to expand this study to hospital/healthcare environments, half way treatment centres/homes with patients having several physical disabilities, incorporating larger sample sizes representing both genders from districts around the country, to cover different socio-cultural backgrounds. Further, continuing this study with different values and intensities of colour Green with prolonged time of exposure, applied in an array of proportions on different surfaces, textures and materials is suggested.

\section{References}

American Psychiatric Association. 2013. Diagnostic and statistical manual of mental disorders (5th ed.). Arlington, VA: American Psychiatric Publishing.

Barrick,C.B, Taylor,D and Correa,E.I. 2002 , Color sensitivity and mood disorders: biology or metaphor? J Affect Disord ;68(1):67-71. doi: 10.1016/s0165-0327(00)00358-x.

Baum, A. 1990, Stress, intrusive imagery, and chronic distress. Health Psychology, 9,653-675.

Birren, F. 1988, Light, color and environment. West Chester: Schiffer

Dearing,B.G \& Singg,S .1996, Photosensitive assessment: a study of color preference, depression and temperament Ph.D. Subtle Energies 6- Energy Medicine, Volume 7.

Department of Census \& Statistics (2012) Census of Population and Housing, Ministry of Policy Planning and Economic Affairs

Lubos,L.2012,The Role of Colors in Stress Reduction, Liceo Journal of Higher Education Research 5(2), DOI: 10.7828/ljher.v5i2.39.

Eiseman, L. (2006). Color: Messages and meanings - A Pantone color resource. Gloucester, MA: Hand Books Press Distributed by North Light Books.

Gebert, F. 1977, Psychologische and physiologische wirkungenvon umgebungsfarben (Psychological and physiological 
effects of surrouinding color). Inaugural-dissertation zur Erlangung des Doktorgrades er Zahnmedizin des Farchbereichs human-medizin der Philipps-Universitat, Marburg.

Itten, J. 1973, The art of color: The subjective experience and objective rationale of color (van Haagen, E. , Trans.). New York, NY: Van Nostrand Reinhold.

Idrees,B and Ilyas, R. 2012, Discrimination and stigmatization of physically disabled student in a general educational environment in pakistan: a case study, Academic Research International, Vol. 2, No. 2. ISSN-L: 2223-9553, ISSN: 2223-9944

Jacobs, K. W. and Suess, J. F. 1975, Effects of Four Psychological Colors on Anxiety States. Perceptual and Motor Skills, vol. 41, 1975, pp. 201-210.

Klotsche C. 1993. Colour Medicine. Arizona: Light Technology Publishing.

Kutchma, Teresa M. 2003). The Effects of Room Color on Stress Perception: Red versus Green Environments," Journal of Undergraduate Research at Minnesota State University, Mankato: Vol. 3 , Article 3.

Lovibond, P. F., \& Lovibond, S. H. (1995). The Structure of Negative Emotional States: Comparison of the Depression Anxiety Stress Scales (DASS) with the Beck Depression and Anxiety Inventories. Behaviour Research and Therapy, 33, 335-343.

Lubos, L.C,. 2012, The Role of Colors in Stress Reduction, Liceo Journal of Higher Education Research, Vol 5 No.2 December 2008 ISSN: 2094-1064.

Mahnke, F. H.1996, Color, environment, and human response: An interdisciplinary understanding of color and its use as a beneficial element in the design of the architectural environment. John Wiley \& Sons.

Masridian,M.H.B. 2019 ,Healing Architecture for Mobility Impaired Through Therapeutic Design, School of Architecture Publications, University Technology Malaysia.

Nagumo, H. 2006, Training and Teaching Courses of Color Design of Colleges and Universities in Japan. Shanghai People's Fine Arts Publishing House,.PubMed/NCBI Google Scholar.

Nightingale, F. 1860, Notes on Nursing: What it is and what it is not, New York: D. Appleton and Company

Nolan, R.F, Dai Y, Stanley PD. 1995, An investigation of the relationship between color choice and depression measured by the Beck Depression Inventory. Percept Mot Skills. 81(3f): 1195-1200.

Pellegrini, R.J., Schauss, A.G., Miller, M.E. 1981, Room Color and Aggression in a Criminal Detention Holding Cell: A Test of the "Tranquilizing Pink" Hypothesis. Journal of Othomolecular Psychiatry, 10, 174-181.

Prabhakar, A. 2013, June 16, Finally, a national survey on mental health disorders in India. Available from: DNA India website: http://www.dnaindia.com/health/report-finally-anational-survey-on-mental-health-disorders-inindia-1848694(accessed 15th May 2021].

Richardson,P.S.2019, The Interrelationships of the Chakras and Mental Health, Journal of Metaphysical Thought Volume II | Number 1.

Starr, C.2005, Biology: Concepts and Applications. Thomson Brooks/Cole. p. 94. ISBN 978-0-534-46226-0.

New York Times .1902 October 26, Use Colors to Cure Insane; Ward's Island Physicians Try Their Effect on Patients. Available from: https://www.nytimes.com/1902/10/26/archives/use-colors-to-cure-insane-wards-islandphysicians-try-their-effect.html

Wexner, L. B. 1954, The degree to which colors (hues) are associated with mood-tones. Journal of Applied Psychology, 38, 432-435White, A. 2011, The Elements of Graphic Design. New York, NY: Allworth Press. pp. 81105. ISBN 978-1-58115-762-8.

WHO.2020, Disability and health. Available from: https://www.who.int/news-room/fact-sheets/detail/disabilityand-health (accessed 20 th June 2021].

Woodson, W. 1981, Human Factors Design Handbook. New York.: McGraw-Hill, Inc.

Wright, A. 1998, The beginner's guide to colour psychology. London: Colour Affects.

Zborowsky,T and Kreitzer, M.J. 2014. Integrative Nursing: Creating optimal healing environments, USA: Oxford University Press .

Zhou, N. 2013, On the Relationship between Color and Physical \& Mental Health. Art Edu Res.; (22): 33-33. PubMed/NCBI 